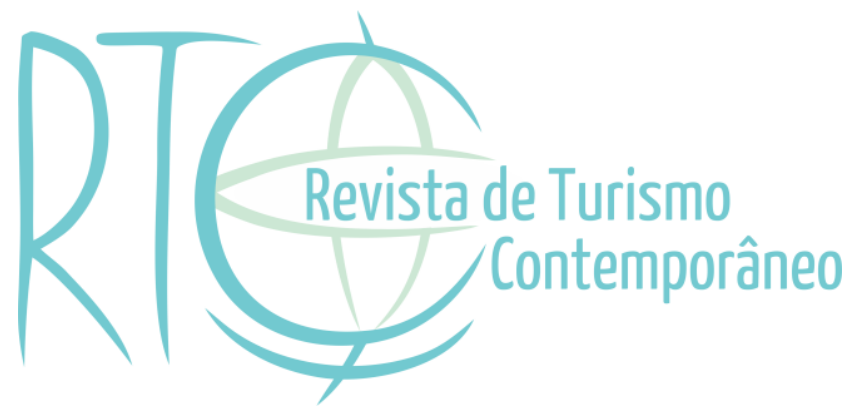

\title{
Fenomenologia nas pesquisas em turismo: análise das dissertações dos programas de pós-graduação no Brasil
}

\section{Phenomenology in tourism research: analysis of postgraduate dissertations in Brazil}

\section{Orlando Alcobia}

Doutorando em Turismo pela Universidade Federal do Rio Grande do Norte - UFRN, Natal/RN, Brasil

E-mail: orlandoalcobia@ufrn.edu.br

\section{Clébia da Silva}

Professora da Universidade Federal do Rio Grande do Norte - UFRN, Natal/RN, Brasil E-mail: clebia@ufrnet.br

\section{Moema Hofstaetter}

Doutoranda em Turismo pela Universidade Federal do Rio Grande do Norte - UFRN, Natal/RN, Brasil

E-mail:moema.natal@hotmail.com

\section{Ana Karina Maia}

Mestranda em Turismo pela Universidade Federal do Rio Grande do Norte - UFRN, Natal/RN, Brasil

E-mail: akakaomaia@gmail.com 


\title{
RESUMO
}

$\mathrm{Na}$ perspectiva de aferir como se vem procedendo metodologicamente e verificar a exata aplicação do método fenomenológico aos estudos em turismo no Brasil, foi realizada neste presente trabalho uma pesquisa de caráter exploratório-descritivo, onde foram analisadas 570 (quinhentos e setenta) dissertações de mestrados acadêmicos, depositadas entre os anos de 2008 e 2016 em todas as instituições aqui examinadas, pertencentes ao território brasileiro. Em um enfoque da busca da compreensão do caminho metodológico foi feita uma análise de dados, observando-se os processos e técnicas utilizadas pelos pesquisadores em questão, tais como entrevistas em profundidade, observação participante e relatos experienciais. Da análise da discussão dos resultados observou-se que, das 570 (quinhentos e setenta) dissertações analisadas, apenas 13 (treze) adotaram o método fenomenológico. Diante deste fato, concluise que, dada a necessidade de um embasamento teórico complexo de seu pesquisador, este método é de pouca aplicação nas instituições envolvidas nesta pesquisa. Ademais, a essencialidade da postura neutra de seu pesquisador dificulta muito a caracterização das pesquisas como adotantes do método.

Palavras-chave: Método Fenomenológico. Turismo. Pesquisa. Dissertações.

\begin{abstract}
This paper brings the perspective of assessing the methodological procedures and verify the exact application of the phenomenological method to studies in the field of tourism in Brazil. An exploratory-descriptive research was carried out, where 570 (five hundred and seventy) dissertations of academic Master's courses, which were deposited between 2008 and 2016 in diverse institutions of Brazilian territory, were examined. The research had focus in understanding the methodological path into a data analysis by observing the processes and techniques used by the researchers involved, utilizing in-depth interviews, participant observation and experiential reports. From the discussion realized we found out that from 570 (five hundred and seventy) dissertations analyzed only 13 (thirteen) had adopted the phenomenological method. Given this fact, we concluded that, given the need for a complex theoretical foundation of the researcher, this method is of little application in the institutions involved in this field. Furthermore, the essential neutral position required for a researcher makes it very difficult to characterize a particular research as conducted by that method.
\end{abstract}

Keywords: Phenomenological Method. Tourism. Research. Dissertations. 


\section{INTRODUÇÃO}

Pernecky e Jamal (2010) fizeram uma pesquisa, em dezembro de 2009, com as palavras-chave "tourist experience"' no Google Scholar o que resultou em 4.920 referências. Esta mesma experiência foi refeita em novembro de 2018, resultando em 30.400 registros. Os achados de 2009 foram considerados significativos no que se refere à experiência para os estudos em turismo, corroborando com o aumento expressivo na consulta feita em 2018, o que remete à pertinência da abordagem fenomenológica, que se importa com a experiência vivida, no turismo que tem na experiência um de seus alicerces. Porém, nos estudos do turismo há uma tendência para a corrente do Positivismo e de caminhos metodológicos influenciados pelas ciências naturais (Nechar, 2011).

Mesmo sendo grande a influência do positivismo, considerando que ser humano é o sujeito dos estudos turísticos e o responsável pela configuração do fenômeno turístico, compreendemos que o método fenomenológico se apresenta com estreita aderência aos estudos do turismo.

Ademais, para Szarycz (2009) é necessário fortalecer os alicerces filosóficos da pesquisa fenomenológica no turismo, evitando situações que possam ir de encontro aos fundamentos da teoria, como exemplo, querer que seus métodos conduzam a pesquisas que levem a objetividade, generalização e realidade ou abstração teórica, em vez de percepções, significados individuais e singularidade. A fenomenologia no turismo tem servido como um caminho teórico para descrever ou compreender a existência experiencial e permanente de turistas, anfitriões, trabalhadores do setor, dentre outros envolvidos no fenômeno turístico, não se limitando a falar de um objeto em si (ex.: o avião), mas de como vemos ele e o mundo e os significados que eles sustentam (a experiência da viagem de avião ao local visitado) (Pernecky \& Jamal, 2010).

A fenomenologia corresponde a uma tendência filosófica que tem origem na Alemanha (século XIX), como um contraponto ao pensamento positivista, como único caminho para fazer ciência. A abordagem da fenomenologia "é uma meditação lógica que visa ultrapassar as próprias incertezas da lógica, com vista e por meio de uma linguagem ou logos que exclua a incerteza" (Lyotard, 1954, p. 10). Para compreender o fenômeno segue-se um caminho, um método, e para isso há duas etapas: não interessa o fato de existir, mas o sentido desse fato, o contrário do Positivismo que os considera importantes por si mesmo. Intuir o sentido é o início do método, sendo possível captá-lo. A segunda etapa diz respeito ao sujeito que faz uma reflexão. 
Para a fenomenologia, como já referido, não interessa o fato, como no positivismo, mas sim o sentido dele, o que significa, segundo Ales Bello (2006, p. 94) "todos os fenômenos, que estão interativamente sendo analisados e também os detalhes internos ao sujeito referentes àqueles fenômenos, as vivências". Na fenomenologia se trabalha o sentido e o significado das coisas que existem, da existência humana.

A fenomenologia apresenta-se, além de uma corrente filosófica, como um método de investigação, com uma abordagem à pesquisa qualitativa, que se preocupa com a compreensão de um grupo social, organização, etc. Nesse sentido a fenomenologia "espera ir além do mundo das aparências e dos conhecimentos teóricos e se aproximar da experiência humana sob novas perspectivas para apreendê-la a partir de sua dimensão existencial, da 'ekstase’, que se anuncia velada" (Graça, 2000, p. 29). O método fenomenológico consiste na investigação dos fenômenos particulares, das essências e apresentação das relações fundamentais entre as essências.

Este trabalho é fundamentado na fenomenologia de Husserl que busca descrever o fenômeno que se mostra na própria consciência, um conhecimento do conhecimento, assim, com base no supracitado, o objetivo do artigo é discutir como se dá a utilização do método fenomenológico nos cursos de pós-graduação em turismo no Brasil.

\section{REFERENCIAL TEÓRICO}

\subsection{A fenomenologia}

Em fins do século 19, Edmund Husserl inicia, a partir da matemática, reflexões do que se chamou Fenomenologia. A palavra 'fenômeno' significa aquilo que se mostra, que se manifesta, diferente de aquilo que parece. Se analisarmos a palavra 'fenomenologia' vamos nos deparar com a terminação 'logia', que deriva de 'logos', palavra grega, que dentre outros significados relaciona-se a pensamento, capacidade de refletir. Disso temos que a fenomenologia é a reflexão, o pensamento sobre algo ou aquilo que se mostra (a nós). O que Husserl observa é que as coisas se mostram e somos nós que pensamos sobre o sentido do que se mostra.

Para Husserl importa mais compreender o sentido do que se mostra do que o fato de se mostrarem. Segundo Ales Bello (2006, p. 19) “o grande problema da filosofia é buscar o sentido das coisas, tanto de ordem física quanto de caráter cultural, religioso, etc, que se mostram a nós". Para compreendermos os fenômenos, Husserl propôs um método, o 
fenomenológico, que delineia um caminho, na busca da compreensão do sentido do que se mostra.

O método fenomenológico é composto de duas etapas: (i) redução eidética (busca o sentido dos fenômenos) e (ii) redução transcendental (compreensão do sujeito).

Na redução eidética, para buscar o sentido dos fenômenos, deixamos de lado tudo que não é o sentido do que queremos compreender. Para Husserl não interessa o fato de existir, mas sim, interessa o sentido do fato de existir. E nisso a fenomenologia se difere principalmente do Positivismo para quem importa o fato como a verdade, sem se preocupar com o sentido dos fatos, importando apenas o fato em si.

Uma vez que na abordagem fenomenológica não se tem em vista a propositura de fatos pré-concebidos, arraigados de ideias de causalidade, repetitividade e controle, é imprescindível que o cientista abandone crenças e juízos anteriores ou pré-concebidos, para explorar simplesmente o fenômeno tal como é dado (Creswell, 1998; Husserl, 1990; Masini, 1997; Ray, 1994). O processo pelo qual se "suspende" essas crenças e juízos é a redução fenomenológica ou epoché. Tem-se então clareza que o método fenomenológico não se norteia por princípios explicativos, teorias consagradas ou disposições descritivas préconcebidas acerca do fenômeno a ser analisado.

E aqui é importante uma referência aos estudos do turismo, como já citado, de forte influência positivista, uma vez que na sua maioria, até muito recentemente eram voltados ao mercado e, para tal, bastava a descrição dos fatos sem uma preocupação com a interpretação dos mesmos (Panosso Netto, 2005).

Podemos afirmar que ao compreender um fato cientificamente compreende-se tudo? $\mathrm{O}$ positivismo diz que sim, a fenomenologia diz que, em geral, não. Para a fenomenologia a compreensão do fato implica na compreensão do sentido desse fato.

$\mathrm{Na}$ tentativa de sintetizar essa etapa da redução eidética, Husserl lembra que a filosofia é a busca do sentido e não apenas dos aspectos do objeto. Portanto, o primeiro passo do método é a intuição, para captar o sentido.

$\mathrm{Na}$ redução transcendental, que busca compreender como é o sujeito que busca o sentido, Husserl se pergunta quem é o sujeito? E essa é a novidade apresentada por Husserl. O objeto, parte distante, de fora do sujeito, a partir da tomada de consciência daquele (o objeto), pelo sujeito, ou melhor, a partir da percepção que o sujeito tem do objeto, este (o objeto) agora passa a ser parte do sujeito. A percepção é resultado do dar-nos conta, que é a consciência de algo. Ao ter consciência estamos na 'relação com'. Podemos refletir sobre essa consciência, e esse refletir é um novo ato, uma nova vivência (Ales Bello, 2006). 
Temos aqui dois níveis de consciência, (i) a consciência dos atos perceptivos e (ii) a consciência dos atos reflexivos. Sendo que o ato reflexivo é uma vivência possível apenas pelos humanos, já que temos a capacidade de perceber e registrar aquilo que percebemos e tomar consciência que estamos vivendo o ato da percepção. A consciência é, pois, a dimensão com a qual registramos os atos. E tudo que vivemos passa pelo registro da consciência.

Posto isso podemos avançar para a compreensão das formas de registros dos atos nas diversas ciências. Husserl afirma que cada ciência se prende, se fixa no seu objeto, em geral, "sem entender qual é o sentido do ser humano e de sua relação com os outros, com a comunidade, com a sociedade, com o Estado" (Ales Bello, 2006, p. 86). Para que este sentido seja compreendido é essencial que o trabalho de análise do objeto seja interdisciplinar. Nesse sentido é importante fazer menção novamente ao turismo, que se apresenta como um campo de estudo interdisciplinar e que poderia se valer do método fenomenológico para qualificar seus estudos.

Ao afirmar que o trabalho de análise do objeto deva ser interdisciplinar, mais uma vez Husserl realiza uma crítica ao Positivismo, quando afirma que o importante é que, já que dificilmente podemos conhecer tudo, que tenhamos a consciência de que se trata de uma parte, e que ainda existem fundamentos a serem reconhecidos (Ales Bello, 2006).

Depois de compreender a complexidade inerente ao embasamento teórico que dá sustentabilidade ao método fenomenológico como saber científico, designadamente no âmbito das ciências sociais, o que diz respeito também ao turismo, é relevante compreender os processos metodológicos e técnicas utilizadas para a sua empirização.

\subsection{O método fenomenológico: processos e técnicas utilizadas}

Depois de discorrer sobre a complexidade inerente ao embasamento teórico que dá sustentabilidade ao método fenomenológico como sendo científico, designadamente no âmbito das ciências sociais e, por conseguinte, do turismo, é relevante discutir os processos metodológicos e técnicas utilizadas para a sua empirização, em todas as etapas da pesquisa como a delimitação da área temática, determinação do problema e objetivos, definição da amostra, a coleta de dados e processamento, análise e interpretação dos dados.

Spiegelberg (1971 como citado em Moreira, 2002) expõe três passos principais para caracterizar o método fenomenológico, independente das variáveis entre os diversos autores (como se nisso houvesse concordância entre todos): 1) Investigação de fenômenos particulares, onde estariam contidas as operações de percepção intuitiva do fenômeno, exame 
analítico e descrição; 2) Investigação de Essências Gerais, fase na qual ocorreria a ideação (processo pelo qual se prossegue do particular para o universal), seguida também de exame analítico e descrição e; 3) Apreensão de relações fundamentais entre as essências, operacionalizada pelo processo denominado variação Imaginativa Livre.

O método, segundo Panosso Netto (2005) é uma atitude ou um posicionamento do pesquisador no desenvolvimento da pesquisa, já que o pesquisador, ao realizar a pesquisa deve se livrar de todos os conceitos e conhecimentos que tem da realidade que será objeto do seu estudo. É o que se chama de processo de époche. Fica evidenciado que não existe um modelo a ser seguido, mas uma atitude do pesquisador no desenvolvimento da pesquisa.

Panosso Netto (2005) sintetiza as inquietações dos pesquisadores do método numa pergunta, qual seja “por que se opta pela escolha do método fenomenológico?”. E apresenta três respostas ao questionamento, a saber, (i) porque como é um método novo na abordagem do turismo, que pode trazer novas possibilidades para esse campo de estudo tão complexo; (ii) por ser um método de reação contra outros reducionistas na análise das sociedades; (iii) pelo método possibilitar investigações universais de essências.

Passador et al. (2010) reforça a necessidade de coerência nos processos metodológicos afirmando que "se, após a definição da problemática, a opção fenomenológica for considerada interessante e pertinente, o pesquisador deve seguir na elaboração de seu plano de trabalho dentro das características e ditames da linha".

$\mathrm{Na}$ primeira etapa de qualquer projeto de pesquisa encontra-se a delimitação do tema. Para Demo (1995) o método fenomenológico é apropriado para pesquisas "sobre o que é mundano, corriqueiro e aceito sem exames, em oposição ao que é raro, irregular, controverso ou intrigante". Coppe (2001, como citado em Macedo \& Boava 2012, p.12) afirma que na fenomenologia "o pesquisador busca compreender o mundo para o sujeito, ou seja: captar significados do mundo desse sujeito a partir da sua descrição do vivido.” Deste modo, é facilmente compreensível que o método fenomenológico se adeque a temáticas inseridas no contexto das relações interpessoais ou mesmo ao insondável mundo interno de cada indivíduo. Assim a fenomenologia encontra-se muitas vezes associada a temas como a psicologia, comportamento organizacional, atividades turísticas, cultura e identidade, estudos sobre percepções, entre outros, isto é, temas que surjam diretamente relacionados com as experiências vivenciadas por cada um e com o efeito causa-consequência no comportamento dos indivíduos.

Depois de definido o tema da pesquisa segue-se a identificação do problema e a definição dos objetivos. Nesse contexto, Las Casas et al. (2016) refere que ao contrário das 
pesquisas clássicas onde a problematização vem sempre em formato de interrogação, na abordagem fenomenológica "o problema não está inteiramente definido, ele expressa uma insatisfação do pesquisador em relação a aquilo que ele pensa saber sobre algo, ou algo o incomoda e lhe causa ansiedade gerando tensão que o leva a buscar a essência do fenômeno". Dessa forma, demonstra que o ponto de partida para qualquer pesquisa fenomenológica se dá a partir de uma inquietação emocional sobre uma realidade que o autor não é capaz de compreender de imediato, na sua totalidade. Segundo o mesmo autor, numa pesquisa fenomenológica, a definição dos objetivos do estudo nunca deverá ser explícita, uma vez que tal abordagem não prevê a operacionalização de conceitos e variáveis. Segundo Amatucci (2009 como citado em Las Casas et al. 2016, p. 213) "falar em objeto e tipo de olhar é mais adequado que falar em objetivo geral e objetivos específicos".

A definição da amostra para Passador et al. (2010) deve respeitar princípios simples e claros: os indivíduos ou grupos selecionados necessitam de possuir características singulares assim como devem ter passado por experiências semelhantes. Pela complexidade da abordagem metodológica da fenomenologia, o tempo requerido para coleta de dados no campo de estudo é vasto. Deste modo, é incomum a existência de um tamanho amostral de grandes dimensões, assim como é rara a ocorrência de amostras unitárias. Geralmente o tamanho da amostra é inferior a 10 indivíduos, mas, há casos, onde pode chegar às 300 pessoas, Creswell (1988 como citado em Passador et al., 2010).

Como anteriormente referido, o modelo fenomenológico tem como principal intuito captar os fenômenos vivenciados por outros e dar um significado às emoções, percepções, sentimentos, empatias ou desencantos por eles gerados. Assim, para Souza e Guedes (2012 como citado em Las Casas et al. 2016, p. 214) o pesquisador tem duas formas de imiscuir-se no fenômeno: “ou o explorador toma a posição da consciência do indivíduo (processo de empatia), assume os seus modelos mentais e experiencia diretamente o fenômeno (...) ou a experiência de um fenômeno é transmitida por meio de símbolos ao explorador pelo ser explorado".

Neste sentido, Macedo e Boava (2012) consideram que a fenomenologia permite dois tipos de instrumentos de coletas de dados: entrevistas e relatos de experiências. De acordo com Las Casas et al. (2016) são múltiplos os tipos de entrevistas que se moldam ao método fenomenológico, quais sejam, (i) entrevistas semi-estruturadas para a captação de símbolos que geram informações e interpretações à medida que os questionamentos vão sendo feitos, (ii) entrevistas em profundidade na procura das dinâmicas das percepções e sentimentos dos entrevistados sobre as suas próprias vivências, (iii) entrevista de história de vida dos 
participantes que parte do princípio que o conhecimento sobre cada indivíduo só é maximizada quando da descrição da sua existência humana e, (iv) entrevista de história oral que visa captar informações sobre indivíduos que pela sua condição social por vezes são excluídos dos relatos, história e documentações oficiais.

Para o mesmo autor instrumentos de captação de som e imagem facilitam de sobremaneira a que haja uma interpretação fidedigna dos dados recolhidos ou mesmo que suscite algumas nuances interpretativas através de expressões faciais ou entoações de voz. Passador et al. (2010) refere que os instrumentos de coleta de dados não devem ser demasiadamente estruturados assim como não se deve formular hipótese antes da coleta, uma vez que tal aparato técnico tende a formatar a visão do pesquisador, inibindo-o assim de captar a essência do que está sendo analisado.

A observação participante, privilegiando uma dinâmica participativa do pesquisador, é outra técnica de coleta de dados bastante usual na fenomenologia. Autores como Passador et al. (2010), Martinez e da Silva (2014) e Macedo et al. (2012) elegem a observação participante como uma técnica adequada pois permite uma estreita interação entre o pesquisador e os sujeitos a serem pesquisados criando uma afinidade entre os dois, facilitando assim a obtenção de depoimentos, histórias e narrativas genuínas, característica essa tão importante para a captação da essência do fenômeno em estudo.

São Caldas e Macêdo (2011, p. 13) que apresentam uma última técnica aplicável pelo método fenomenológico, técnica essa desenvolvida por Mauro Amatuzzi (1996) e apelidada de Versão de Sentido, consistindo num "relato livre, que não tem a pretensão de ser um registro objetivo do que aconteceu, mas sim de ser uma reação viva a isso, escrita ou falada imediatamente após o ocorrido, e como uma palavra primeira".

O primeiro passo para realizar uma correta análise e interpretação dos dados é organizá-los de forma adequada no intuito de simplificar a leitura dos mesmos. Passador et al. (2010) afirma que os dados depois de recolhidos podem ser organizados por categorias, temas ou tipologias. Para Las Casas et al. (2016) a organização dos dados deve decorrer à medida que a análise dos mesmos vai sendo feita, recorrendo à constituição de unidades de significação. As unidades de significação são etapas sucessivas que visam direcionar o sentido das interpretações, sendo as mesmas "expressas na linguagem comum dos participantes da pesquisa".

A análise dos dados possui um forte carácter qualitativo. Perante as premissas da fenomenologia o pesquisador deve ser capaz de adotar uma atitude neutra perante os dados recolhidos, de acordo com Santaella (2012 como citado em Martinez e Silva 2014, p.14) 
"descrevendo pormenorizadamente as essências no modo como elas aparecem à intuição", realizar a tal "epoché" e despir-se de qualquer presunção de conhecimentos anteriores que impeçam o atingir de interpretações que desencadeiem significações imprevistas da realidade.

Por último, Martinez e Silva (2014) declaram ser extremamente importante que os resultados obtidos através do método fenomenológico sejam comunicados ou divulgados à comunidade objeto de estudo. Tal procedimento visa a maximização da autoestima dos indivíduos que participaram na pesquisa assim como desenvolve a autoconsciência pessoal e social da realidade que os rodeia.

\subsection{A fenomenologia e sua relação com o turismo}

Após a compreensão de que a escolha do método a ser utilizado em determinada pesquisa está a cargo do pesquisador, de acordo com seus objetivos e convicções científicas, e que, importa a coerência entre o método utilizado e os processos e as técnicas utilizadas, para o reconhecimento da pesquisa, é necessário que haja conhecimento das possibilidades metodológicas, suas vantagens e limitações.

Em se tratando de turismo, objeto desta análise, afirma-se que há poucos autores que se preocupam com a epistemologia do turismo e com qual método melhor se adequa para os estudos do turismo. Neste sentido importa aqui relacionar a fenomenologia enquanto método, que pode em muito, contribuir para os estudos do fenômeno do turismo, pois oferece a oportunidade de aprofundar a compreensão da experiência (Pernecky \& Jamal, 2010).

Umbilicalmente associada ao rigor científico em suas pesquisas, a fenomenologia é um método científico iluminador, onde se deseja um aprofundamento que vai além de análises superficiais ou visões tidas como rasteiras sem o rigor necessário imprescindível ao que se pretende.

Apesar de se apresentar como um diferencial em matéria pertinente às aplicações em estudos que desvelam o fenômeno e o compreendem em sua inteireza, este método fenomenológico, no qual se procede com eficiência criteriosa em busca de uma efetiva eficácia, se apresenta como extremamente complexo e de difícil aplicação.

Neste contexto é que se traz à lume essa dificuldade em sua escolha como método de pesquisa, constatando-se que a metodologia a ser escolhida é de livre alvedrio de seu pesquisador e que este por sua complexidade não se torna um método atraente pelo seu grau de dificuldade e que, também existe deficiência na sua própria aplicabilidade, que por vezes não se dá de modo correto por falta de percepções acerca da sua execução. 
Sua utilização como método de conhecimento no que lhe é concernente ao estudo do turismo, não é diferente, sendo de fácil observância a sua pouca utilização em trabalhos científicos, bastando, para se observar isso, uma busca documental em universidades e faculdades onde haja o turismo em sua composição da grade de cursos oferecidos, tal qual foi utilizado aqui neste artigo.

O método fenomenológico apresenta-se como alternativa, sendo uma postura investigativa em produção de todas as áreas do conhecimento, e em matéria de turismo, se faz essencial sua aplicação, dada a carência em estudos epistemológicos associados ao turismo e, a necessidade de uma condução diferenciada para que estes trabalhos se tornem mais profundos e com mais propriedade em sua cientificidade.

Apesar de haver poucos adeptos na aplicação do método no estudo da epistemologia do turismo, a utilização deste vem a oferecer notáveis benefícios para os esforços que possam vir a ser envidados, no sentido de obter conhecimento em busca da compreensão deste fenômeno, com muito ainda a ser elucidado, haja vista a multidisciplinariedade que faz do fenômeno turístico um sistema de trocas envolventes, mas que ao mesmo tempo o torna um pouco indefinido, dada sua fisionomia multifacetada e complexa, visto que não possui ainda um objeto de estudo definido e caraterizado, permitindo assim a precariedade e a necessidade da compreensão e aplicabilidade do fenômeno turístico, este que se apresenta como social, de relações interpessoais e interdependentes.

Por outro ângulo, por ser o turismo caracterizado como fenômeno social, segundo o entendimento de Krippendorf (2009)

\footnotetext{
O turismo moderno tornou-se um dos fenômenos mais notáveis e singulares de nossa época. Para descobrir sua natureza, é necessário tentar compreender como se conectam os elementos, quais são as causas e os efeitos, os desejos e as realidades. Devemos, antes de mais nada, dominar o mecanismo de seu funcionamento, antes de determinar os meios de controlá-lo, modificá-lo e aperfeiçoá-lo (Krippendorf, 2009, p.18).
}

Já que "o método fenomenológico propicia um tratamento multidimensional, transdisciplinar e inter-relacional e é ao mesmo tempo crítico, rigoroso e sistemático" (Passador et al., 2010) e, sendo considerada uma metodologia que capta de modo eficaz a experiência humana e a sua relação com o ambiente em que estamos inseridos, este se apresenta muito interessante como fonte basilar para os estudos relativos ao fenômeno turístico, tendo em vista que o turismo tem como enfoque primário a experiência humana do turista, do autóctone ou do profissional que provê os serviços (Moreira, 2002). 
Ademais, ao não restringir os pesquisadores como, por exemplo, ocorre nas abordagens positivistas, a postura fenomenológica vem a alcançar dados mais apurados sob perspectivas transdisciplinares e multidisciplinares.

Buscando encontrar o significado das coisas, a fenomenologia aplicada ao turismo, pode vir a contribuir com a exclusão de muitas lacunas que envolvem este fenômeno, carente ainda de análises mais aprofundadas e compreensões mais apuradas acerca dele e do que lhe influencia.

Turismo e método fenomenológico se dialogarem juntos tendem a caminhar no sentido de construir novos contornos à própria fisionomia do fenômeno turístico como hoje nos é apresentado, encontrando sentido para a natureza do turismo e soluções para as problemáticas que porventura venham a aparecer no estudo detalhado dele.

Tendo em vista o problema histórico da deficiência relacionada à construção do conhecimento em turismo, já que para se conceber alicerces científicos mais bem definidos se faz necessária uma sólida reflexão filosófica, o método fenomenológico aqui aplicado traria uma segurança maior à epistemologia produzida nesta área em crescente desenvolvimento de suas bases teóricas e carente ainda de saber científico abalizado.

De acordo com Tribe (1997, p. 369) a epistemologia em turismo é importante por dois motivos, primeiro porque "promove uma revisão sistemática do que é o legítimo conhecimento turístico" (...) e segundo porque "ainda não há acordo sobre o mapa ou as fronteiras dos estudos turísticos". Diante deste pensamento, se observa a importante contribuição a ser dada pelo método fenomenológico através da sua aplicação em estudos turísticos, uma vez que este método poderá imprimir um rigor científico fundamental à produção do conhecimento desejado à esta seara do saber.

Ademais, neste contexto são geradas reflexões críticas ao conhecimento até então produzido, podendo vir a apontar o que realmente é concreto e verdadeiro ou sem fundamento para a compreensão do mapa e das fronteiras em estudos aplicados ao fenômeno turístico.

\section{METODOLOGIA}

Esta pesquisa tem um caráter exploratório-descritivo, sua utilização é feita quando o pesquisador quer familiarizar-se com o fenômeno estudado, a fim de chegar a uma nova compreensão deste (Selltiz, 1974). A abordagem foi mista: a) quantitativa por ter sido feito um estudo bibliométrico, que segundo Guedes e Borschiver (2005), é uma técnica de levantamento de dados estatísticos, contagem sobre conteúdos bibliográficos, visando quantificar os processos de comunicação escrita. Além disso, para Vanti (2002) também 
Fenomenologia nas pesquisas em turismo: análise das dissertações dos programas de pós-graduação

pode-se analisar com essa técnica a webometria, as citações, co-citações, palavras correlatas e agrupamentos bibliográficos. Para este trabalho o critério de seleção dos materiais foram: i) dissertações de mestrado acadêmico defendidas entre 2008 e 2016 em programas de pósgraduação no Brasil, conforme dados obtidos na plataforma Sucupira, sendo assim desconsiderados os mestrados profissionalizantes e doutorados, houve, ainda, programa que teve seu início no anos da coleta de dados, logo não havia nenhuma defesa (Tabela 1), ii) com um dos seguintes descritores em seu resumo - fenomenologia, fenomenológica e fenomenológico no resumo ou metodologia do trabalho, visto que por vezes a apalavra não aparecia no resumo, mas na metodologia.

O período de tempo foi definido com base no ano da primeira defesa do Programa de Pós-Graduação em Turismo da Universidade Federal do Rio Grande do Norte - primeiro mestrado específico em Turismo em instituição pública do país.

Tabela 1 - Quantidade de programas e cursos de pós-graduação em Turismo por instituição

\begin{tabular}{|c|c|c|c|c|c|c|c|c|c|c|c|c|c|c|}
\hline \multirow[b]{2}{*}{ Nome da IES } & \multirow[b]{2}{*}{ Sigla } & \multirow[b]{2}{*}{$\mathrm{UF}$} & \multicolumn{7}{|c|}{ Total de Programas de pós-graduação } & \multicolumn{5}{|c|}{$\begin{array}{l}\text { Totais de Cursos de pós- } \\
\text { graduação }\end{array}$} \\
\hline & & & Total & $\mathrm{ME}$ & $\mathrm{DO}$ & MP & DP & $\begin{array}{c}\mathrm{ME} / \\
\mathrm{DO} \\
\end{array}$ & $\begin{array}{r}\mathrm{MP} / \\
\mathrm{DP}\end{array}$ & Total & $\mathrm{ME}$ & DO & MP & $\mathrm{DP}$ \\
\hline $\begin{array}{l}\text { Instituto Federal de } \\
\text { Educação, Ciência e } \\
\text { Tecnologia de Sergipe }\end{array}$ & IFS & $\mathrm{SE}$ & 1 & 0 & 0 & 1 & 0 & 0 & 0 & 1 & 0 & 0 & 1 & 0 \\
\hline $\begin{array}{l}\text { Universidade Anhembi } \\
\text { Morumbi }\end{array}$ & UAM & $\mathrm{SP}$ & 2 & 0 & 0 & 1 & 0 & 1 & 0 & 3 & 1 & 1 & 1 & 0 \\
\hline $\begin{array}{l}\text { Universidade de } \\
\text { Caxias do Sul }\end{array}$ & UCS & $\mathrm{RS}$ & 1 & 0 & 0 & 0 & 0 & 1 & 0 & 2 & 1 & 1 & 0 & 0 \\
\hline $\begin{array}{l}\text { Universidade de São } \\
\text { Paulo }\end{array}$ & USP & $\mathrm{SP}$ & 1 & 1 & 0 & 0 & 0 & 0 & 0 & 1 & 1 & 0 & 0 & 0 \\
\hline $\begin{array}{l}\text { Universidade do Vale } \\
\text { do Itajaí }\end{array}$ & Univali & $\mathrm{SC}$ & 1 & 0 & 0 & 0 & 0 & 1 & 0 & 2 & 1 & 1 & 0 & 0 \\
\hline $\begin{array}{l}\text { Universidade Estadual } \\
\text { do Ceará }\end{array}$ & UECE & $\mathrm{CE}$ & 1 & 0 & 0 & 1 & 0 & 0 & 0 & 1 & 0 & 0 & 1 & 0 \\
\hline $\begin{array}{l}\text { Universidade Federal } \\
\text { de Pernambuco }\end{array}$ & UFPE & $\mathrm{PE}$ & 1 & 1 & 0 & 0 & 0 & 0 & 0 & 1 & 1 & 0 & 0 & 0 \\
\hline $\begin{array}{l}\text { Universidade Federal } \\
\text { do Paraná }\end{array}$ & UFPR & PR & 1 & 1 & 0 & 0 & 0 & 0 & 0 & 1 & 1 & 0 & 0 & 0 \\
\hline $\begin{array}{l}\text { Universidade Federal } \\
\text { do Rio Grande do } \\
\text { Norte }\end{array}$ & UFRN & $\mathrm{RN}$ & 1 & 0 & 0 & 0 & 0 & 1 & 0 & 2 & 1 & 1 & 0 & 0 \\
\hline $\begin{array}{l}\text { Universidade Federal } \\
\text { Fluminense }\end{array}$ & UFF & $\mathrm{RJ}$ & 1 & 1 & 0 & 0 & 0 & 0 & 0 & 1 & 1 & 0 & 0 & 0 \\
\hline \multicolumn{3}{|l|}{ Totais } & 11 & 4 & 0 & 3 & 0 & 4 & 0 & 15 & 8 & 4 & 3 & 0 \\
\hline
\end{tabular}

Fonte: Plataforma Sucupira (https://sucupira.capes.gov.br, recuperado em 16, nov., 2018)

ME: Mestrado Acadêmico

DO: Doutorado Acadêmico

MP: Mestrado Profissional

DP: Doutorado Profissional

ME/DO: Mestrado Acadêmico e Doutorado Acadêmico 
MP/DP: Mestrado Profissional e Doutorado Profissional

As bases de dados utilizadas foram os sites dos programas de pós-graduação, onde os materiais estavam disponibilizados ou nos sites das bibliotecas das instituições quando não havia disponibilização direto do site do programa. O levantamento foi feito entre julho e agosto de 2017. As etapas da pesquisa foram: a) verificação nos sites dos programas conforme os parâmetros definidos; b) identificação dos descritores; c) seleção da dissertação e d) análise. Desta forma foram encontradas 570 dissertações, das quais 491 disponíveis para análise, sendo apenas 13 que citavam a fenomenologia, como mostra a Tabela 2.

Tabela 2 - Quantidade de Dissertações por Instituição

\begin{tabular}{|c|c|c|c|c|}
\hline Instituição de Ensino & $\mathbf{U F}$ & Ano & $\begin{array}{c}\text { Quantidade de } \\
\text { dissertações vinculadas } \\
\text { aos programas de } \\
\text { Turismo }\end{array}$ & $\begin{array}{l}\text { Quantidade encontrada de } \\
\text { dissertações que referem-se à } \\
\text { fenomenologia }\end{array}$ \\
\hline \multirow{9}{*}{$\begin{array}{l}\text { Universidade Anhembi } \\
\text { Morumbi (UAM) }\end{array}$} & \multirow{9}{*}{ SP } & 2008 & 9 & 1 \\
\hline & & 2009 & 15 & sem referência \\
\hline & & 2010 & 17 & 1 \\
\hline & & 2011 & 18 & sem referência \\
\hline & & 2012 & 26 (3 indisponíveis) & sem referência \\
\hline & & 2013 & 13 & sem referência \\
\hline & & 2014 & 12 & sem referência \\
\hline & & 2015 & 25 & sem referência \\
\hline & & 2016 & 15 & 1 \\
\hline \multicolumn{2}{|l|}{ Total } & \multicolumn{3}{|c|}{147} \\
\hline $\begin{array}{l}\text { Universidade de Brasília } \\
\text { (UNB) }\end{array}$ & DF & & & sem referência \\
\hline \multirow{9}{*}{$\begin{array}{l}\text { Universidade de Caxias do } \\
\text { Sul (UCS) }\end{array}$} & \multirow{9}{*}{$\mathrm{RS}$} & 2008 & 13 (1 indisponível) & sem referência \\
\hline & & 2009 & 11 (2 indisponíveis) & sem referência \\
\hline & & 2010 & 6 & 1 \\
\hline & & 2011 & 9 (2 indisponíveis) & sem referência \\
\hline & & 2012 & 11 (2 indisponíveis) & sem referência \\
\hline & & 2013 & 11 & sem referência \\
\hline & & 2014 & 9 (2 indisponíveis) & sem referência \\
\hline & & 2015 & 9 & sem referência \\
\hline & & 2016 & 12 & sem referência \\
\hline \multicolumn{2}{|l|}{ Total } & \multicolumn{3}{|c|}{91} \\
\hline $\begin{array}{l}\text { Universidade de São Paulo } \\
\text { (USP) }\end{array}$ & & 2016 & 6 & 1 \\
\hline \multirow{9}{*}{$\begin{array}{l}\text { Universidade do Vale do } \\
\text { Itajaí (UNIVALI) }\end{array}$} & \multirow{9}{*}{$\mathrm{SC}$} & 2008 & 13 (1 indisponível) & sem referência \\
\hline & & 2009 & 8 & sem referência \\
\hline & & 2010 & 31 (1 indisponível) & sem referência \\
\hline & & 2011 & 10 (2 indisponíveis) & sem referência \\
\hline & & 2012 & 14 (1 indisponível) & sem referência \\
\hline & & 2013 & 33 (1 indisponível) & sem referência \\
\hline & & 2014 & 13 (4 indisponíveis) & 4 \\
\hline & & 2015 & 2 (todas indisponíveis) & 1 \\
\hline & & 2016 & 0 & sem referência \\
\hline
\end{tabular}


Fenomenologia nas pesquisas em turismo: análise das dissertações dos programas de pós-graduação

\begin{tabular}{|c|c|c|c|c|}
\hline \multicolumn{2}{|l|}{ Total } & \multicolumn{3}{|c|}{130} \\
\hline \multirow{3}{*}{$\begin{array}{l}\text { Universidade Federal do } \\
\text { Paraná (UFPR) }\end{array}$} & \multirow{3}{*}{ PR } & 2014 & 9 (todas indisponíveis) & sem referência \\
\hline & & 2015 & 2 (todas indisponíveis) & sem referência \\
\hline & & 2016 & 9 (todas indisponíveis) & sem referência \\
\hline \multicolumn{2}{|l|}{ Total } & \multicolumn{3}{|c|}{20} \\
\hline \multirow{9}{*}{$\begin{array}{l}\text { Universidade Federal de } \\
\text { Minas Gerais }\end{array}$} & \multirow{9}{*}{ MG } & 2008 & 1 (todas indisponíveis) & sem referência \\
\hline & & 2009 & 9 (2 indisponíveis) & sem referência \\
\hline & & 2010 & 9 (4 indisponíveis) & sem referência \\
\hline & & 2011 & 12 (2 indisponíveis) & sem referência \\
\hline & & 2012 & 12 (3 indisponíveis) & sem referência \\
\hline & & 2013 & 26 (16 indisponíveis) & sem referência \\
\hline & & 2014 & 7 (todas indisponíveis) & sem referência \\
\hline & & 2015 & 0 & sem referência \\
\hline & & 2016 & 18 (14 indisponíveis) & sem referência \\
\hline \multicolumn{2}{|l|}{ Total } & \multicolumn{3}{|c|}{94} \\
\hline \multirow{7}{*}{$\begin{array}{l}\text { Universidade Federal do Rio } \\
\text { Grande do Norte (UFRN) }\end{array}$} & \multirow{7}{*}{$\mathrm{RN}$} & 2010 & 9 & 1 \\
\hline & & 2011 & 9 & sem referência \\
\hline & & 2012 & 13 & sem referência \\
\hline & & 2013 & 12 & sem referência \\
\hline & & 2014 & 13 & 1 \\
\hline & & 2015 & 20 & 1 \\
\hline & & 2016 & 12 & sem referência \\
\hline \multicolumn{2}{|l|}{ Total } & \multicolumn{3}{|c|}{88} \\
\hline $\begin{array}{l}\text { Universidade Federal } \\
\text { Fluminense (UFF) }\end{array}$ & $\mathrm{RJ}$ & \multicolumn{3}{|c|}{ Programa iniciado em 2015. Sem defesa. } \\
\hline \multicolumn{2}{|l|}{ Total Geral } & \multicolumn{3}{|c|}{570} \\
\hline
\end{tabular}

Fonte: Elaborado com base nas informações dos sites das universidades, 2017.

Após esta fase da pesquisa, a abordagem foi qualitativa, onde para a análise do material foi elaborado o seguinte protocolo (Tabela 3):

Tabela 3 - Protocolo de Análise

\begin{tabular}{|c|c|c|c|}
\hline \multicolumn{4}{|l|}{ Autor, ano } \\
\hline \multicolumn{4}{|l|}{ Título do Trabalho } \\
\hline \multicolumn{4}{|l|}{ Objetivo Geral } \\
\hline \multicolumn{4}{|l|}{ IES/Programa } \\
\hline \multicolumn{4}{|c|}{ Itens de Análise } \\
\hline Objetivo 1 & Objetivo 2 & Objetivo 3 & \\
\hline $\begin{array}{l}\text { 1. Método } \\
\text { Utilizado }\end{array}$ & $\begin{array}{l}\text { 1. Método } \\
\text { Utilizado }\end{array}$ & $\begin{array}{l}\text { 1. Método } \\
\text { Utilizado }\end{array}$ & \\
\hline $\begin{array}{l}\text { 2. Instrumento de } \\
\text { coleta (entrevista } \\
\text { em } \\
\text { profundidade?) }\end{array}$ & $\begin{array}{ll}\text { 2. Instrumento de } \\
\text { coleta } \\
\text { (entrevista em } \\
\text { profundidade?) }\end{array}$ & $\begin{array}{l}\text { 2. Instrumento de } \\
\text { coleta (entrevista } \\
\text { em } \\
\text { profundidade?) }\end{array}$ & \\
\hline 3. Sujeitos da coleta & $\begin{array}{l}\text { 3. Sujeitos da } \\
\text { coleta }\end{array}$ & $\begin{array}{l}\text { 3. Sujeitos da } \\
\text { coleta }\end{array}$ & \\
\hline $\begin{array}{l}\text { 4. Aspectos do } \\
\text { trabalho de } \\
\text { campo }\end{array}$ & $\begin{array}{l}\text { 4. Aspectos do } \\
\text { trabalho de } \\
\text { campo }\end{array}$ & $\begin{array}{l}\text { 4. Aspectos do } \\
\text { trabalho de } \\
\text { campo }\end{array}$ & \\
\hline 5. Resultado & 5. Resultado & 5. Resultado & \\
\hline $\begin{array}{l}\text { 6. Conclusão (fez } \\
\text { referência à } \\
\text { Fenomenologia) }\end{array}$ & $\begin{array}{ll}\text { 6. } & \text { Conclusão (fez } \\
\text { referência à } \\
\text { Fenomenologia) }\end{array}$ & $\begin{array}{l}\text { 6. Conclusão (fez } \\
\text { referência à } \\
\text { Fenomenologia) }\end{array}$ & \\
\hline
\end{tabular}


A partir da avaliação realizada tendo por base o protocolo de análise, as treze dissertações foram agrupadas em três categorias distintas, quais sejam, A) citou, explicou e relacionou os resultados e/ou considerações finais com o os princípios da abordagem fenomenológica; B) além de citar explicou em que consiste o método fenomenológico na metodologia, mas não fez mais referência a ele no decorrer do trabalho e C) apenas citou que a sua dissertação utilizou o método fenomenológico, mas não explicou o que era e não fez nenhuma referência no trabalho.

\section{ANÁLISE E DISCUSSÃO DOS RESULTADOS}

Para análise e discussão dos resultados parte-se de 13 dissertações dentre o universo pesquisado, que estavam relacionadas ao método fenomenológico e que são apresentadas abaixo (Tabela 4):

Tabela 4 - Dissertações válidas para análise

\begin{tabular}{|c|c|c|c|c|}
\hline & Instituição & Ano & Autor(a) & Título da Dissertação \\
\hline 1 & Universidade Vale do Itajaí & 2014 & Alessandra Felini & $\begin{array}{l}\text { Análise dos Fatores } \text { Intrínsecos do } \\
\text { Marketing de Destino que } \\
\text { Potencializam o Segmento do } \\
\text { Turismo de Luxo em Balneário } \\
\text { Camboriú - SC }\end{array}$ \\
\hline 2 & Universidade Vale do Itajaí & 2014 & Idalina Boni & $\begin{array}{l}\text { Desafios para Incrementar a } \\
\text { Associação do Turismo À Economia } \\
\text { Solidária: A Experiência do Cepesi } \\
\text { em Itajaí/SC }\end{array}$ \\
\hline 3 & Universidade Vale do Itajaí & 2014 & Vilton Souza & $\begin{array}{l}\text { Olhares Cruzados: O } \\
\text { Histórico de São Luís Sob a Lente } \\
\text { dos Atores Turísticos }\end{array}$ \\
\hline 4 & Universidade Vale do Itajaí & 2014 & Umberto Paganella & $\begin{array}{l}\mathrm{O} \text { Congresso dos Gideões } \\
\text { Missionários: Turismo Religioso? }\end{array}$ \\
\hline 5 & Universidade Vale do Itajaí & 2015 & Lílian Paiva & $\begin{array}{l}\text { A Comensalidade dos Rituais na } \\
\text { Festa do Divino Espírito Santo em } \\
\text { Alcântara }- \text { MA } \\
\text { Potencialidade Turística }\end{array}$ \\
\hline 6 & $\begin{array}{l}\text { Universidade de Caxias do } \\
\text { Sul }\end{array}$ & 2010 & Marcela Marinho & $\begin{array}{l}\text { O Conceito de Turismo Sexual na } \\
\text { Perspectiva de Sua Inserção como } \\
\text { Objeto de Estudo na Gradução em } \\
\text { Turismo }\end{array}$ \\
\hline 7 & $\begin{array}{l}\text { Universidade Federal do Rio } \\
\text { Grande do Norte }\end{array}$ & 2010 & Tatiana Mortiz & $\begin{array}{lrr}\text { Turismo no } & \text { Espaço Rural e } \\
\text { Comunidades } & \text { Tradicionais: Uma } \\
\text { Análise das } & \text { Percepções } & \text { da } \\
\text { Comunidade do Catu/RN } & \end{array}$ \\
\hline 8 & $\begin{array}{l}\text { Universidade Federal do Rio } \\
\text { Grande do Norte }\end{array}$ & 2014 & Maria de Góis & $\begin{array}{l}\text { Turismo Religioso: Análise das } \\
\text { Políticas Governamentais e Ações } \\
\text { Eclesiais no Monumento de Uruaçu } \\
\text { em São Gonçalo - RN }\end{array}$ \\
\hline 9 & $\begin{array}{l}\text { Universidade Federal do Rio } \\
\text { Grande do Norte }\end{array}$ & 2015 & Ivana Guedes & $\begin{array}{l}\text { Questionamentos Acerca de Valores } \\
\text { Axiológicos no Turismo: Uma } \\
\text { Abordagem } \\
\text { Hermenêutica }\end{array}$ \\
\hline 10 & Universidade de São Paulo & 2016 & Taysa Godinho & $\begin{array}{l}\text { Cidade Patrimônio da Humanidade e } \\
\text { Desenvolvimento }\end{array}$ \\
\hline
\end{tabular}




\begin{tabular}{c|c|c|c|l}
\hline & & & & $\begin{array}{l}\text { Percepções Sobre a Realidade de } \\
\text { Diamantina, MG }\end{array}$ \\
\hline 11 & $\begin{array}{c}\text { Universidade Anhembi } \\
\text { Morumbi }\end{array}$ & 2008 & Roberta Sogayar & $\begin{array}{l}\text { Hospitalidade no Ensino Superior em } \\
\text { Turismo: Estudo de Caso do } \\
\text { Programa Tourism Education Future } \\
\text { Iniciative }\end{array}$ \\
\hline 12 & $\begin{array}{c}\text { Universidade Anhembi } \\
\text { Morumbi }\end{array}$ & 2010 & Nilton Filho & $\begin{array}{l}\text { Análise do Processo de Atuação do } \\
\text { SEBRAE-SP no Desenvolvimento do } \\
\text { Turismo na Área de Proteção } \\
\text { Ambiental Capivari-Monos a Partir } \\
\text { da Teoria dos Sítios }\end{array}$ \\
\hline 13 & $\begin{array}{c}\text { Universidade Anhembi } \\
\text { Morumbi }\end{array}$ & 2016 & Andréa Leandro & $\begin{array}{l}\text { Hospitalidade e Movimentos } \\
\text { Migratórios } \\
\text { Contemporâneos em Maria Da Fé - } \\
\text { MG (1990-2015) }\end{array}$ \\
\hline
\end{tabular}

Fonte: Elaboração própria.

Desta forma, analisando as 13 dissertações de mestrado acima referidas, com base no protocolo de análise obteve-se a seguinte classificação: categoria A) 5 dissertações; categoria B) 3 dissertações e categoria C) 5 dissertações.

Nesta perspectiva, das 491 dissertações disponíveis analisadas, pertencentes a programas de pós-graduação em turismo, 13 propuseram-se a desenvolver uma metodologia fenomenológica, das quais somente 5 conseguiram cumprir de forma meticulosa os procedimentos metodológicos inerentes a uma investigação científica fenomenológica, algo que segundo Passador et al. (2010) é fundamental para o alcance do sucesso investigativo, uma vez que o método fenomenológico encerra uma grande complexidade.

Como se pode observar pelos títulos das dissertações identificadas como fenomenológicas, uma boa parte dos temas escolhidos encontra-se condizente com o preconizado por Demo (1995) e Coppe (2001, como citado em Macedo e Boava 2012) ao versarem sobre fenômenos inerentes às relações interpessoais, ou intrínseco a cada indivíduo, como as percepções, os valores, os olhares ou os comportamentos, constituindo-se assim como pesquisas de carácter qualitativo, descritivo e exploratório.

Contudo, observou-se que a maioria dos treze autores identificados optou por começar a sua pesquisa fazendo uso de uma pergunta de partida evidente, assim como desenhou objetivos de pesquisa concretos, sendo esses passos metodológicos que não encontram respaldo em Las Casas et al. (2016) e Amatucci (2009 como citado em Las Casas et al. 2016), que afirmam que os mesmos podem retirar dos pesquisadores a flexibilidade necessária para compreender os fenômenos observados sob prismas nunca antes imaginados.

Quanto às definições das amostras todas elas respeitaram o aconselhado por Creswell (1988 como citado em Passador et al., 2010) tanto nas características dos indivíduos selecionados como no tamanho amostral. Porém, no que tange aos instrumentos de coleta de 
dados, poucas foram as opções utilizadas. A generalidade dos autores cingiu-se à utilização de entrevistas em profundidade e pesquisas participantes que permitiram a descrição exaustiva dos fenômenos por si presenciados.

Os instrumentos sugeridos por Las Casas et al. (2016) como entrevistas de história de vida, entrevistas de história oral ou tecnologias de imagens e som foram pouco aplicados. A técnica apelidada de Visão de Sentido, desenvolvida por Mauro Amatuzzi (1996), também não foi utilizada. Todavia, é possível ressaltar a utilização por parte de um autor da técnica de mapas mentais, técnica essa bastante interessante e adequada ao método fenomenológico.

Nas análises e interpretação dos resultados poucos foram também os autores que conseguiram descrever como efetuaram a "epoché" e qual o processo de construção de unidades de significação de resultados, etapas essas de extrema relevância conforme advogam Santaella (2012 como citado em Martinez e da Silva 2014) e Las Casas et al. (2016).

É de salientar que das treze dissertações classificadas como metodológicas, onze pertencem somente a três universidades distintas, sendo elas Universidade Vale do Itajaí, Universidade Federal do Rio Grande do Norte e Universidade Anhembi Morumbi. Assim, é de passível interpretação que o método fenomenológico associado às pesquisas em turismo no Brasil ainda não está disseminado, vivendo de pesquisas pontuais e focalizadas em instituições específicas cujos programas de pós-graduação são "fenomenologicamente" mais despertos.

\section{CONSIDERAÇÕES FINAIS}

O método fenomenológico vem se mostrando como alternativa a outros métodos científicos que visam à construção da realidade; como é o caso dos métodos positivista, dialético, estruturalista, entre tantos outros que podem ser de utilização do pesquisador.

Pela observação e análise das dissertações, constatou-se que, embora ainda em movimento incipiente, o turismo vem ganhando adeptos ao método fenomenológico, que se bem compreendido e aplicado pode vir a contribuir em muito na busca da compreensão da realidade deste fenômeno, que se revela como complexa e multifacetada.

No entanto observa-se ainda que há carência de estudos, no caso dissertações, com clareza de orientação para o uso do método fenomenológico, haja vista a complexidade do embasamento teórico que dá sustentabilidade ao método e sua complicada aplicabilidade.

Esta afirmação é embasada tendo em vista o número de dissertações disponíveis nos diversos programas de pós-graduação em turismo que somam, no período de 2008 a 2016, um 
total de 491 dissertações, sendo que a aproximação com o método fenomenológico é verificada em apenas 13 dissertações, o que representa $0,02 \%$ do total disponível, sendo este montante irrisório em relação ao todo que se apresenta. Diante do exposto, constata-se que a fenomenologia vem sendo subutilizada na produção do conhecimento científico afeto ao turismo e, de maneira geral, mesmo que haja professores nas universidades que incentivem e estimulem a utilização do método fenomenológico em sua essência não vem sendo aplicado a contento e, se utilizado, carece das técnicas adequadas e do conhecimento necessário e imprescindível à sua adequada aplicação.

Ademais se constata que as dissertações analisadas contêm muitas limitações e equívocos de compreensão, que as tornam cada vez mais distantes da aplicação exata do método fenomenológico.

Provavelmente a não escolha dos pesquisadores pela utilização do método fenomenológico em dissertações, dada sua complexidade, seja um dos fatores mais determinantes desta postura. Mas entende-se que é possível em nível de mestrado, fazer pesquisas de essência fenomenológica. É mais esperado, apesar da dificuldade de compreensão do método e de sua aplicação, para além de uma análise descritiva mais profunda, que houvesse um número mais significativo de dissertações utilizando esse método.

Apesar de trabalhos importantes nacionais e internacionais apontarem para a importância da abordagem fenomenológica em estudos do turismo e, somando-se a isto o que já foi observado acima com base na análise realizada, que haja a necessidade de uma maior e melhor orientação para a utilização do método fenomenológico. Assim como o esclarecimento de que o cientista deve ter muito cuidado para a utilização do método fenomenológico, uma vez que ele exige muita experiência por parte do pesquisador para fazer a correta opção da estratégia de investigação e também a característica determinante na postura deste pesquisador, que deverá ter um olhar neutro para a pesquisa.

Como o objeto do turismo é essencialmente a experiência humana, seja o viajante, o fornecedor de serviços ou o habitante do destino turístico, a fenomenologia pode contribuir, em muito, com esse tipo de análise da realidade, que é interdisciplinar, desde que se tenha conhecimento do método fenomenológico e coerência na orientação e utilização do mesmo. 


\section{REFERÊNCIAS}

Ales Bello, A. A. (2006). Introdução à fenomenologia. Bauru, SP: Edusc.

Caldas M., \& Macêdo S. (2011). Uma Análise Crítica Sobre as Técnicas de Pesquisa Fenomenológica Utilizadas em Psicologia Clínica. Revista do Nufen, 1(1), 3-16. Belém: UFPa.

Creswell, J. W. (1998). Qualitative inquiry and research design: choosing among five traditions. Thousand Oaks: Sage Publications.

Demo, P. (1995) Metodologia científica em ciências sociais. São Paulo: Atlas.

Graças, E. M. (2000). Pesquisa qualitativa e a perspectiva fenomenológica: fundamentos que norteiam sua trajetória. Revista Mineira de Enfermagem, 4(1/2), 28-33.

Guedes, V., \& Borschiver, S. (2005). Bibliometria: uma ferramenta estatística para a gestão da informação e do conhecimento, em sistemas de informação, de comunicação e de avaliação científica e tecnológica. II Anais do Encontro Nacional de Ciência da Informação, Salvador, $1-18$.

Husserl. E. (1990). A ideia da Fenomenologia. Lisboa: Edições 70.

Krippendof, J. (2009). Sociologia do turismo: para uma nova compreensão do lazer e das viagens. (3a. ed. rev. e ampli). São Paulo: Aleph.

Las Casas A., Siani, S., \& Correa D. (2016). Fenomenologia, Método Fenomenológico e Pesquisa Empírica: o instigante universo da construção do conhecimento esquadrinhada na experiência da vida. Revista de Administração da UNIMEP, 14(1), 193-219. Piracicaba: UNIMEP.

Lyotard, J. F. (1954). A fenomenologia. Lisboa: Edições 70.

Macedo F., \& Boava D. (2012). Fenomenologia Social: possibilidades para a pesquisa organizacional. Anais do VII Encontro de Estudos Organizacionais da ANPAD. Curitiba: EnEO.

Macedo F., Boava D., \& Antonialli L. (2012). A Fenomenologia Social na Pesquisa Estratégica. Revista de Administração Mackenzie, 13(5), 171-203. São Paulo: UPM.

Martinez M., \& Silva P. (2014). Fenomenologia: o uso do método em comunicação. Anais do XII Congresso de la Asociación Latinoamericana de Investigadores de la Comunicación. Lima: ALAIC.

Masini, E. F. S. (1997). Enfoque fenomenológico de pesquisa em educação. In: Fazenda, I. Metodologia da pesquisa educacional. (4a. ed.). São Paulo: Cortez.

Moreira, D. A (2002). O método fenomenológico na pesquisa. São Paulo: Pioneira Thomson Learning. 
Fenomenologia nas pesquisas em turismo: análise das dissertações dos programas de pós-graduação

Nechar, M. C. (2011). Epistemología critica del turismo ¿qué es eso?. Turismo em Análise, 22 (3), 516-538.

Panosso Netto, A. (2005). Filosofia do Turismo: Teoria e Epistemologia. São Paulo: Aleph.

Passador, J., Medeiros, M., \& Becheleni D. (2010). A Fenomenologia e a Pesquisa em Turismo: reflexões para a aplicação com base no turismo gastronômico. Revista Turismo em Ação, 13(1), 20-34. Vale do Itajaí: Univali.

Pernecky, T., \& Jamal, T. (2010). (Hermeneutic) Phenomenology in Tourism Studies. Annals of Tourism Research, 37(4), 1055-1075.

Ray, M. A. (1994). The richness of phenomenology: philosophic, theoretic and methodological concerns. In: Morse, J. M. Critical issues in qualitative research methods. London: Sage Publications.

Selltiz, C., Jahoda, M., Deutsch, M., \& Cook, S. (1974). Métodos de pesquisa nas relações sociais. São Paulo: E.P.U.

Szarycz, G. (2009). Some issues in tourism research phenomenology: a commentary. In: Current issues in tourism, 12, 47 -58.

Tribe, J. (1997). The indiscipline of tourism. Annals of Tourism Research, 24(3), 638-657.

Vanti, N. A. (2002). Da bibliometria à webometria: uma exploração conceitual dos mecanismos utilizados para medir o registro da informação e a difusão do conhecimento. Ciência da Informação, Brasília, 31(2), 152-16

FORMATO PARA CITAÇÃO DESTE ARTIGO

SILVA, C., ALCOBIA, O., HOFSTAETTER, M., \& MAIA, A. K. (2018). Fenomenologia nas pesquisas em turismo: análise das dissertações dos programas de pós-graduação no Brasil. Revista de Turismo Contemporâneo, 6(2), 270-290. 